\title{
Análisis constitucional del indulto y la conmutación de penas. ¿Qué requisitos se deben cumplir para su legítima emisión?
}

\section{POR ESTEBAN FEDERICO TAGLIANETTI (*)}

\begin{abstract}
Sumario: I. Palabras preliminares.- II. Objeto del trabajo.- III. Definición de las figuras, diferenciación respecto de la amnistía y vinculación con otros conceptos.- IV. El indulto y la conmutación de penas, desde un punto de vista constitucional.- V. Requisitos constitucionales.- VI. Propuesta.- VII Conclusiones.- VII. Bibliografía.
\end{abstract}

Resumen: el presente trabajo apunta a esclarecer cuáles son los requisitos que deben concurrir para la legítima emisión de dos institutos específicos -el indulto y la conmutación de penas-, que fueron interpretados en formas disímiles por la doctrina y por la jurisprudencia. Además, partiendo de una visión integral del texto constitucional y desde una perspectiva que contempla la defensa de los derechos humanos, postulamos, por un lado, la necesidad de imposibilitar su aplicación ante casos específicos - como ser, por ejemplo, los crímenes de lesa humanidad, los delitos contra la administración pública, entre otros-y también ante determinadas personas, tales como funcionarios públicos. Por otro lado, incluimos nuevas exigencias para que se puedan aplicar los institutos del indulto y de la conmutación de penas. Específicamente consideramos pertinente participar a la víctima y/o a sus familiares y realizar audiencias públicas previas a la toma de decisión por parte del presidente. Finalmente, recogiendo lo expuesto, presentamos un proyecto de norma que regula su emisión, despejando las interpretaciones disímiles, mediante un decreto autónomo dictado por el Ejecutivo, que - a su vez- sirve de autolimitación.

Palabras claves: indulto - conmutación de penas - atribuciones del poder ejecutivo - crímenes de lesa humanidad - derechos humanos

(*) Abogado, Universidad Nacional de La Plata. Esp. en Derecho Administrativo, Universidad Católica de La Plata. Esp. en Derecho Constitucional, Universidad Nacional de La Plata. Prof. Adjunto Constitucional profundizado, Carrera de Especialización en Derecho Administrativo, Universidad Católica de La Plata. Prof. de la Escuela de la Procuración del Tesoro de la Nación. Miembro del Instituto de Derecho Constitucional y Político, Facultad de Ciencias Jurídicas y Sociales, Universidad Nacional de la Plata. 
Constitutional analysis of pardon and commutation of sentences. What requirements must be met for their legitimate issuance?

Abstract: the present work aims to clarify which requirements must prevail when making a legitimate issue of two specific legal institutions (Pardon and Commutation of Sentences) which were dissimilarly interpreted by doctrine and case-law. Moreover, taking as starting point a global view of the constitutional text and from a perspective which considers the defense of human rights, we claim, on the one hand, for the need to make its application impossible before specific cases such as, for instance, crimes against humanity, against public administration, among others, as well as before certain people alike public officials. On the other hand, we include new demands so that pardon and commutation of sentences can be applied. We particularly deem relevant to inform the victim and/or relatives and to hold public hearings prior to the decisions made by the President. Finally, and in view of the above, we submit a draft standard, which regulates its issue removing any dissimilar interpretations, through an official decree issued by the Executive Branch which, in turn, serves as a self-restraint.

Keywords: pardon - commutation of sentences - powers to the executive branch - crimes against humanity - Human Rights

\section{Palabras preliminares}

Debido a que la temática que abordaremos a continuación es controvertida, consideramos necesario señalar, preliminarmente, que nos pronunciamos contrarios a la existencia de la emisión del indulto y de la conmutación de penas. Tal como argumentamos anteriormente (Taglianetti, 2018), creemos sumamente necesario eliminar esta competencia vetusta del abanico de atribuciones del Poder Ejecutivo nacional. Sin embargo, atentos a su persistencia, consideramos oportuno analizar las mencionadas figuras jurídicas y proponer una norma que las regule, con el objetivo último de estrechar el marco de su actuación habilitante.

\section{Objeto del trabajo}

El presente trabajo tiene por objeto analizar el instituto del indulto y el de la conmutación de penas, así como también dar cuenta de las problemáticas que causa su ilimitada aplicación. A tal fin, en primer lugar, nos abocaremos a definirlos, haciendo especial hincapié en la diferencia existente entre éstos y el instituto de la amnistía. Luego, nos adentraremos a examinar la naturaleza jurídica de las dos figuras jurídicas mencionadas, tomando en consideración la opinión de la doctrina en nuestro país. Además, incorporaremos al análisis dos elementos que, desde nuestro punto de vista, resultan necesarios para comprender cabalmente 
ANÁLISIS CONSTITUCIONAL DEL INDULTO Y LA CONMUTACIÓN DE PENAS. ¿QUÉ REQUISITOS SE DEBEN CUMPLIR PARA SU LEGÍTIMA EMISIÓN? - ESTEBAN FEDERICO TAGLIANETTI (PP. 195-224)

el tema, nos referimos a los conceptos de "víctima" e "impunidad". Seguidamente, analizaremos los requisitos que deben concurrir para que la emisión del acto constitucional sea válida. Por último, a modo de propuesta, promoveremos las bases para una norma que regule los institutos mencionados, recogiendo las interpretaciones y opiniones dadas a lo largo del presente trabajo.

\section{Definición de las figuras, diferenciación respecto de la amnistía y vinculación con otros conceptos}

\section{III.1. Indulto y conmutación de penas: definiciones}

En el artículo 99 inciso 5, la Constitución Nacional faculta al Poder Ejecutivo de la Nación a indultar y conmutar penas, en los siguientes términos: "Puede indultar o conmutar las penas por delitos sujetos a la jurisdicción federal, previo informe del tribunal correspondiente, excepto en los casos de acusación por la Cámara de Diputados". A su vez, el texto constitucional otorga al Congreso de la Nación la atribución de "conceder amnistías generales" (artículo 75, inciso 20).

Para tener una comprensión más cabal de las implicancias de esas figuras jurídicas, pasaremos revista a las definiciones de indulto y de conmutación de penas dadas en la doctrina nacional.

Por empezar, el maestro Germán Bidart Campos (1993) define estas figuras en los siguientes términos: "El indulto es conceptuado como el perdón absoluto de la pena ya impuesta; y la conmutación, como el cambio de una pena mayor por otra menor" (p. 336). Por su parte, Sánchez Viamonte (1959) indica que "indultar quiere decir anular los efectos de una condena judicial en cuanto a la aplicación de la pena, y conmutar significa sustituir una pena legal por otra menor" (p. 303). A su turno, González (1951) señala: "la posible imperfección de la justicia, y en que después del dictado de su fallo, pueden descubrirse circunstancias que antes de él fueron desconocidas, y cambiar la gravedad del crimen o disminuirlo: reconoce en la justicia no escrito en las leyes, para quitarles lo que tienen de inexorable o riguroso" (p. 542).

Tomando en consideración estas interpretaciones, podemos indicar que, en nuestra opinión, el indulto consiste, básicamente, en un perdón o gracia de la pena impuesta por sentencia firme, y que la conmutación de penas supone la modificación de una pena por otra menor, ya sea en el quantum o en la calidad de la pena. Es pertinente mencionar que, al conmutarse la calidad, ambas penas deben estar previstas como alternativas en el tipo penal en cuestión (por ejemplo, multa y prisión). Caso contrario, el Ejecutivo estaría irguiéndose en legislador. 
A lo dicho, debemos apontocar que el Código penal estipula, en el artículo 68, que el indulto extinguirá la pena y sus efectos, con excepción de las indemnizaciones debidas a particulares. Sentado ello, diremos que la amnistía, por el contrario, extingue la acción penal y hace cesar la condena y todos sus efectos, mientras que, también, deja a salvo las indemnizaciones civiles que puedan corresponder a terceros (Código Penal, artículo 61). Al decir de Lazzarini (1989), la amnistía es "ley de olvido, que trae aparejada la amnesia total de una o varias acciones penadas, como si no hubiera existido y lo actuado no hubiera sido punible, de ahí que se diga con razón, que borra la acción penal y si hubiera dictado sentencia, también a ésta" (p. 1117).

Desde nuestro punto de vista, la amnistía es el acto constitucional por el cual el Congreso decide extinguir determinadas acciones penales, como también las penas que se hubieren impuesto a los autores penalmente responsables (Constitución Nacional (CN), artículo 75, inciso 20).

A partir de ello, es posible afirmar que el constituyente dispuso que el indulto (individual y total) y la conmutación de penas (individual y parcial) figuren como competencias del Poder Ejecutivo, mientras que la amnistía (general y total) es competencia exclusiva del Poder Legislativo.

\section{III.2. Conceptos vinculados}

En este acápite complementaremos el análisis de la figura del indulto y conmutación de penas con la referencia a dos conceptos que estimamos necesarios para comprender la temática en cuestión en todas sus dimensiones. Nos referiremos a los términos de "víctima" e "impunidad". La inclusión del primero responde a la importancia y necesidad - desde nuestro punto de vista - de incluir una instancia previa a la otorgación del indulto o la conmutación de penas que visibilice el parecer de la víctima en relación con la decisión judicial adoptada. Con respecto al segundo concepto, el de impunidad, su contemplación en este trabajo se debe justamente a que el indulto y la amnistía se presentan, desde nuestra concepción, como mecanismos encubridores de una falta de castigo a los culpables, es decir, suponen un acto de impunidad. En este sentido, sostendremos que, de ser aplicadas estas figuras, debe ser únicamente para casos de delitos menores y, de ningún modo, para delitos de lesa humanidad.

\section{III.2.1. Concepto de "víctima"}

Siguiendo los lineamientos del derecho internacional de los derechos humanos, podemos afirmar que "víctima" es, en términos generales, toda persona que ha sufrido un daño como efecto de un accionar ilícito, de manera individual o 
colectiva, bien sea en su patrimonio, en su vida, en su integridad física o en el goce de sus derechos humanos. El término también comprende a la familia inmediata o a las personas a cargo de la víctima directa.

Por su parte, el actual Reglamento de la Corte Interamericana de Derechos Humanos - aprobado en noviembre de 2009-(1) define a la "víctima" como "la persona cuyos derechos han sido violados de acuerdo con la sentencia proferida por la Corte". Por su parte, en la Argentina, mediante la ley No 27.372 se ha definido al concepto de la siguiente manera:

Artículo 2: Se considera víctima: a) A la persona ofendida directamente por el delito; b) Al cónyuge, conviviente, padres, hijos, hermanos, tutores o guardadores en los delitos cuyo resultado sea la muerte de la persona con la que tuvieren tal vínculo, o si el ofendido hubiere sufrido una afectación psíquica o física que le impida ejercer sus derechos.

A partir de este concepto, en lo que hace a este trabajo y teniendo en cuenta la aplicación que tuviera en el pasado el indulto, afirmamos que las víctimas deben ser oídas de manera previa a que se decida dar la gracia o perdón. Conexo a ello, la víctima deberá ser asistida gratuitamente, en caso de que no tenga abogados de parte, para que pueda practicar todas las diligencias que considere pertinente para hacer valer sus derechos.

Estimamos que es una manera razonable de compatibilizar la atribución presidencial y los derechos de la víctima, en un marco de un estado de derecho constitucional.

\section{III.2.2. Concepto de "impunidad"}

La Real Academia Española define el término "impune" del siguiente modo: "Que queda sin castigo". Por su parte, la Corte Interamericana de Derechos Humanos ha definido a la impunidad como la "Falta en su conjunto de investigación, persecución, captura, enjuiciamiento y condena de los responsables de las violaciones de los derechos protegidos por la Convención Americana" (Corte Interamericana de Derechos Humanos, caso Bámaca Velásquez vs. Guatemala, 2000, párrafo 131).

Así, considerando la última definición transcripta, podemos afirmar que, por parte del ordenamiento jurídico de un país, el término no se limita a la falta o

(1) La Corte aprobó el mencionado documento en su LXXXV Período Ordinario de Sesiones (16 al 28 de noviembre de 2009). 
ausencia de una pena o sanción a los autores de un delito, sino que abarca, además, la obligación que tienen los Estados miembros de investigar realmente los hechos generadores de violaciones a los derechos humanos. Especial consideración debemos hacer, en este punto, respecto a los genocidas indultados en nuestro país en el final de la década del ochenta e inicios de los noventa.

Cabe aclarar, entonces, que el indulto o la amnistía pueden —potencialmente- constituirse en mecanismos constitucionales para permitir la impunidad de determinadas personas. De allí, nuestra preocupación por limitar esta atribución constitucional a los delitos denominados menores, evitando su utilización para proteger o liberar a personas que hayan cometido crímenes aberrantes, como ocurrió aquí, mediante los decretos № 1002/89, 1003/89 y 1004/89, que dieron lugar a los fallos de la Corte Suprema: inicialmente, avalaron su constitucionalidad -a saber: "Riveros" (Fallos: 313:1392) y "Aquino" (Fallos: 315:2421) - y, luego, se pronunciaron en sentido opuesto, en los casos "Mazzeo" (Fallos: 330:3248), "Videla" (Fallos: 333:1657), entre otros.

En breves palabras, podemos apuntar que en el fallo "Mazzeo" (2) se resolvió confirmar la sentencia dictada por la Cámara Nacional de Casación Penal, por la cual se había declarado la inconstitucionalidad del decreto 1002/1989, que dispuso el indulto de - entre otros-Santiago O. Riveros. En dicha oportunidad, la Corte sostuvo que los principios derivados de la Constitución Nacional, de los tratados internacionales y de la interpretación y jurisprudencia de la Corte Interamericana llevaron a dicho cuerpo a, en primer lugar, reconocer el carácter imprescriptible de los delitos de lesa humanidad ( $v$. "Arancibia Clavel", Fallos 327:3312); en segundo lugar, declarar la inconstitucionalidad de las Leyes de Obediencia Debida y Punto Final (“Simón", Fallos 328:2056); y, finalmente, replantear el alcance de la garantía

(2) El Juzgado Federal No 2 de San Martín había hecho lugar a la presentación que perseguía la declaración de inconstitucionalidad del decreto 1002/89, mediante el cual el Poder Ejecutivo Nacional indultó, entre otros, a Santiago Omar Riveros, por los hechos a él imputados en la ex causa 85 de la Cámara Federal de Apelaciones de San Martín. La defensa de Riveros, con fundamento en la excepción de cosa juzgada, apeló el pronunciamiento. La Cámara Federal de Apelaciones de San Martín acogió el recurso con sustento en que ese tribunal ya se había expedido en la causa 85 acerca de la validez del indulto presidencial. Apelado este nuevo pronunciamiento, por distintos grupos de querellantes, la Sala II de la Cámara Nacional de Casación Penal se pronunció por la inconstitucionalidad del citado decreto de indulto 1002/89. Contra este último fallo se dedujo el recurso extraordinario federal que origina las actuaciones que son objeto de este comentario. La Corte Suprema de Justicia de la Nación, en la sentencia que nos ocupa, trasciende la cuestión de la constitucionalidad del indulto en cuestión y se pronuncia, en línea con sus precedentes inmediatos, sobre el nuevo alcance del sistema de fuentes en nuestro ordenamiento jurídico después de la reforma constitucional de 1994, así como la configuración jurídica de los delitos de lesa humanidad y como dicha configuración influye directamente sobre clásicos principios del proceso penal como la cosa juzgada y el $n e$ bis in idem. 
ANÁLISIS CONSTITUCIONAL DEL INDULTO Y LA CONMUTACIÓN DE PENAS. ¿QUÉ REQUISITOS SE DEBEN CUMPLIR PARA SU LEGÍTIMA EMISIÓN? - ESTEBAN FEDERICO TAGLIANETTI (PP. 195-224)

de cosa juzgada compatible con los delitos investigados ("Videla", Fallos 326:2805). En consecuencia, prosiguiendo el orden de fundamentación mencionado, el Tribunal sostuvo que los delitos allí investigados, quedan fuera de los alcances de decisiones discrecionales de cualquiera de los poderes del Estado (léase, indulto o amnistía) que impidan la aplicación de las penas a sus autores (3).

En el fallo "Videla", se siguió la línea argumental precedentemente expuesta.

En efecto, los autores deben ser procesados, juzgados y condenados a penas apropiadas en un plazo razonable. Asimismo, en ese camino, se les debe garantizar a las víctimas recursos eficaces, a fin de hacer efectivo el derecho a conocer la verdad, a obtener la reparación de los perjuicios sufridos y a tomar todas las medidas necesarias para evitar la repetición de dichas violaciones.

\section{El indulto y la conmutación de penas, desde un punto de vista constitucional}

A partir de lo expresado en la Constitución Nacional sobre los institutos del indulto y de la conmutación de penas, así como también tomando en cuenta las diferenciaciones mencionadas respecto de la amnistía, podemos afirmar que:

1) La competencia de emitir el indulto y la conmutación de penas es exclusiva y excluyente del Poder Ejecutivo.

2) Esta competencia se encuentra limitada por los requisitos expresos e implícitos de la Constitución, cuya violación acarrea la inconstitucionalidad del acto. Es decir, el Poder Ejecutivo puede indultar, pero su competencia — a diferencia de lo que ocurre en Estados Unidos- no puede instrumentar una amnistía indirecta, ni una intromisión en causa judicial abierta. Caso contrario, se estaría practicando una violación a la reserva de las atribuciones o competencias concedidas expresamente a otros poderes del Estado.

3) La competencia asignada debe interpretarse a luz de los restantes principios y reglas establecidos por la Constitución. En especial, en lo que respecta a los institutos examinados, por lo dispuesto en los siguientes artículos del texto fundamental: 109 (donde se prohíbe el ejercicio de la función judicial por parte del presidente o sus órganos dependientes), 29 (referido a la imposibilidad de que se

(3) Los doctores Carlos S. Fayt y Carmen Argibay, por la minoría, coinciden en sostener la existencia de cosa juzgada y el ne bis in idem, pero se diferencian de la mayoría en que esta última tiene la convicción de que los decretos de indulto son efectivamente inconstitucionales; sólo que entiende que debe prevalecer el principio de la cosa juzgada, por su naturaleza de instituto constitucional y preservando el valor de la seguridad jurídica. 
le atribuya facultades extraordinarias o la suma del poder a persona alguna) y 23 (que expresamente prohíbe la posibilidad de que el presidente aplique penas, aun en estado de sitio).

4) Se controvierte el orden establecido en la Constitución tanto cuando se ejerce una facultad reservada a los Gobiernos Provinciales, como cuando se invade la zona asignada a otro órgano.

5) El indulto o la conmutación de penas pueden solamente recaer sobre delitos de la jurisdicción federal. Es decir, las Provincias pueden regular este instituto en sus constituciones, pero no tienen competencia para amnistiar, conforme la distribución de competencias hecha por la norma federal.

6) El indulto o conmutación es personal, no puede ser general, pues, en tal caso, se estaría violando el artículo 75 , inciso 20 , que le atribuye tal facultad al Poder Legislativo federal.

7) Estos institutos sólo puede alcanzar a condenados, excluyéndose la posibilidad de hacerlo a procesados.

8) Atento a que la Constitución establece que el presidente tiene la atribución para el dictado de los indultos o de la conmutación de penas, se sigue que éste no puede delegarla en ninguna otra persona. La Corte ha dicho esto en el fallo "Luengo" (Fallos: 6: 227).

\section{Requisitos constitucionales}

En el inciso 5 del artículo 99 se enumeran expresamente los siguientes requisitos para otorgar el indulto o la conmutación de penas: 1) que se trate de delitos sujetos a jurisdicción federal; 2) que cuente con un informe previo del tribunal interviniente; 3) se exceptúan los casos de acusación por la Cámara de Diputados. Como punto 4) tenemos que contar con una sentencia pasada en autoridad de cosa juzgada - pero como veremos, esto surge de la interpretación de la cláusula constitucional-. A su vez, hay que señalar que - en virtud de lo normado en el artículo $1^{\circ}$ de nuestra Constitución- se requiere, además de: 5) motivación y 6) publicidad. Posteriormente, como elemento 7) debemos mencionar los casos en que no procede, es decir, no son susceptibles de indulto. Al listado, es necesario agregar un requisito implícito -8) consentimiento del beneficiario- y otros dos requerimientos que, si bien no cuentan con previsión constitucional, es —desde nuestro punto de vista- prudente considerarlos: 9) participación de la víctima en el procedimiento y 10) audiencia pública previa. A continuación, analizaremos en detalle cada uno de los casos enumerados. 
ANÁLISIS CONSTITUCIONAL DEL INDULTO Y LA CONMUTACIÓN DE PENAS. ¿QUÉ REQUISITOS SE DEBEN CUMPLIR PARA SU LEGÍTIMA EMISIÓN? - ESTEBAN FEDERICO TAGLIANETTI (PP. 195-224)

\section{V.1. Delitos sujetos a jurisdicción federal}

El texto de la Comisión Redactora del Congreso Constituyente tenía una variante, no menor, cuando señalaba que quedaban comprendidos en la figura los delitos "cometidos contra la Confederación". Fue gracias a la lúcida intervención de José Benjamín Gorostiaga que la norma tiene la actual configuración. El destacado jurista y político mencionado observó "que la mente de la comisión había sido conceder al ejecutivo la facultad de conmutar las penas por delitos sujetos a la jurisdicción federal; que en esta virtud proponía sustituir, en vez de las palabras: 'cometidos contra la Confederación', las de 'sujetos a la jurisdicción federal', y puesto a votación en esta forma, resultó unánimemente aprobado" (Ravignani, 1937, p. 532).

Esta diferencia y otras que describiremos posteriormente le dan una fisonomía propia y autóctona a la figura en análisis, diferenciándose así del modelo norteamericano - esquema que influyó decididamente en nuestro texto-. En efecto, la Constitución de Estados Unidos tiene una redacción diferente. El artículo 2, secc. 1, cl. 1, in fine, señala: "tendrá poder para acordar la suspensión de castigos y perdones por delitos contra los Estados Unidos, excepto en caso de juicio político". La diferencia entre este texto y el nuestro es notable, incluso la redacción más amplia de esta cláusula ha llevado a que la Corte Norteamericana extienda la competencia a la figura de amnistía (conf. fallo "Garland"; 2- Ex parte Garland, 4 Wallace, 333 [1867]). Su amplitud es mayor a la nacional.

El indulto presidencial sólo puede recaer sobre delitos de jurisdicción federal, excluyendo - como no podía ser de otra manera- los delitos de jurisdicción provincial. Ello responde, correctamente, al esquema de distribución de las esferas de ambas jurisdicciones. Consecuentemente, una intromisión del Poder Ejecutivo Nacional sobre la materia implicaría una violación al federalismo reconocido en la Constitución nacional —conforme los artículos 5, 75 (inciso 12), 121, 123 y 126 de nuestra Constitución Nacional-.

Asimismo, la práctica constitucional muestra que esta facultad se extendió a las infracciones o faltas administrativas, aun cuando estas no constituyen delitos. Así, entre otras, fueron indultadas o conmutadas las infracciones aduaneras, impositivas o de carácter económico. Nos oponemos a tal interpretación, pues el texto nos indica que sólo es posible utilizar los institutos frente a los delitos. En las faltas administrativas se ve con mayor nitidez la desviación, ya que todo se inicia y concluye en el mismo órgano: el presidente - o uno de sus Ministros- sanciona y, a la vez, es el propio Poder Ejecutivo el que indulta o conmuta. Por el contrario, en el caso de los delitos, quien investiga y sanciona es el Poder Judicial y el Poder Ejecutivo, llegado el caso, indulta o conmuta las penas. La diferenciación de los sujetos 
intervinientes y el procedimiento no es menor. Sin embargo, pese a la posibilidad de indultar infracciones, la Corte Suprema ha dicho en el caso "Soto" (Fallos: 313:421) que no es posible indultar en materia de jurisdicción disciplinaria militar (Sagüés, 2017, p. 639).

Por último, diremos que, a partir de la reforma de 1994, el Poder Ejecutivo Nacional no puede indultar o conmutar delitos cometidos en la Ciudad Autónoma de Buenos Aires.

\section{V.2. Informe del Tribunal}

El informe previo tiene como objetivo proporcionar al Poder Ejecutivo los elementos relevantes que le permitan llegar a una decisión informada, es decir, a una toma de decisión racional. Resulta ser una verdad evidente que, a mayor información, mayor probabilidad de adoptar una solución correcta.

El informe no es vinculante para el presidente, aun cuando el tribunal o juez penal se manifiesten en sentido negativo, el Poder Ejecutivo podrá concederlo. De allí la naturaleza jurídica del informe, a saber, un dictamen —es decir, una opinión y juicio que se emite sobre el tema-.

\section{V.2.1. Requisito expreso de la Constitución}

Asimismo, es pertinente mencionar que el informe del Tribunal es uno de los requisitos que expresamente figuran en el texto constitucional. La Constitución señala que debe haber un informe, el mismo debe ser previo al dictado del acto. En consecuencia, si se omite el procedimiento estará viciado. Debemos indicar, por último, que el informe debe ser presentado por escrito, en idioma nacional, con la rúbrica de los jueces intervinientes e indicando el lugar y fecha en que se realizó.

\section{V.2.2. Contenido del informe}

Desde nuestra perspectiva el informe deberá detallar, como mínimo, la siguiente información:

- Individualización del Tribunal informante, Departamento Judicial, especificando su integración y si ésta coincide o no con el que oportunamente dictó la sentencia condenatoria. Fechas de las audiencias y del juicio oral - en caso que los hubiere- y copia certificada de la sentencia dictada. 
- Datos del Condenado: nombre y apellido, DNI, edad, estado civil, personalidad del condenado. Antecedentes penales: descripción del delito y la pena impuesta, mención del número de causa y órganos judiciales que hayan intervenido, sentencia condenatoria pasada en autoridad de cosa juzgada, descripción pormenorizada del delito - tiempo, lugar y metodología empleada-, circunstancias agravantes o atenuantes consideradas, pruebas obrantes en la causa, especificación de si estuvo o no en prisión preventiva - en caso afirmativo, el auto que así lo dispuso- - y de si hubo o no víctima u ofendido por el delito cometido. hechos.

- Cualquier otro dato que pueda servir para la mejor ponderación de los

\section{V.2.3. Solicitud de información complementaria}

El Poder Ejecutivo podrá, cuando así lo considere, requerir los siguientes puntos que, a nuestro entender, resultan sumamente necesarios para lograr tener un conocimiento pleno de la causa:

1) Opinión del Tribunal respecto de la pertinencia de conceder el indulto, el cual revestirá la naturaleza jurídica de consejo o dictamen no vinculante.

2) Informe de la Máxima Autoridad del Establecimiento Carcelario sobre la conducta del condenado, el que también se considerará un consejo de carácter no vinculante para el presidente.

3) Informes médicos, psicológicos y psiquiátricos de la persona a indultar.

4) Expediente judicial.

Entendemos que la competencia para la solicitud de esta información complementaria surge de manera implícita del texto constitucional, pues, si el Poder Ejecutivo debe de manera previa solicitar un Informe al Tribunal de la causa, consideramos que tiene la potestad suficiente para ampliar los elementos a ponderar. Esa información le permitirá, en definitiva, obtener un cúmulo mayor de información sobre la situación frente a la cual deberá definir.

Como señalamos anteriormente, contar con una mayor cantidad de información veraz y completa sobre los hechos que dieron lugar a la condena, supone un aumento de la probabilidad de que la decisión a tomar, respecto de la concesión o no del indulto, sea la correcta. El presidente debe identificar adecuadamente la información relevante, calculando con precisión el hecho y las consecuencias de su decisión - ya sea a favor o en contra-, y procurando que la decisión sea completamente racional. Para ello, el presidente debe evitar intromisiones indebidas, 
es decir, corresponde que sortee las cuestiones políticas coyunturales y la presión de los medios de comunicación o grupos de interés interfieran negativamente en la toma de decisión.

La toma de decisión consiste, básicamente, en elegir una de las soluciones disponibles - que, en el caso del indulto, se reducen a dos- a los efectos de resolver la petición traída a decisión. Cabe puntualizar que, pese a que el Tribunal informe o desaconseje el otorgamiento de la medida, el Poder Ejecutivo no se encuentra limitado por éste. Repetimos que el informe no es vinculante, sino que, justamente, es un mero consejo o dictamen. Lo dicho no implica, en modo alguno, que -a pesar de no ser vinculante- se pueda omitir en el procedimiento de este, ya que es pedido expresamente por la Constitución. Su omisión o su defectuoso cumplimiento acarrean la nulidad insalvable de lo actuado.

Su omisión o presentación imperfecta acarrea la nulidad absoluta. Situación que no podrá ser subsanada a posteriori pues, en tal caso, se habrá omitido su análisis. No importa si, con posterioridad, el presidente no cambia su parecer, basta su omisión para que se dé el caso de nulidad insalvable.

En el caso "Ibáñez", la Corte ha sostenido:

El "previo informe del tribunal correspondiente" constituye un trámite esencial para el ejercicio de la facultad de indultar que el artículo 86, inciso $6^{\circ}$ de la Constitución Nacional confiere al presidente de la Nación. La Constitución Nacional, al no especificar sobre qué puntos ha de recaer el informe que prescribe en su artículo 86 , inciso $6^{\circ}$, ha dejado librado a la discreción del Tribunal si ha de limitarse a hacer mención de las circunstancias de la causa, como es de práctica (y ocurrió en el caso), o bien si ha de emitir opinión sobre la conveniencia o inconveniencia del indulto solicitado (Fallos: 136: 244).

Además, en el mismo fallo, el Máximo Tribunal ha señalado que el objeto del informe es dotar de información necesaria para que la atribución presidencial sea practicada con prudencia y justicia, evitando así que la decisión se funde en un ardid o engaño.

\section{V.3. Acusación de la Cámara de Diputados}

Sobre el particular, debemos decir que la exclusión expresa del texto constitucional funciona como un requisito negativo, es decir, no debe concurrir para que proceda. 
Con este piso, entendemos que indulto y la conmutación no resultan viables cuando se trate de condenados por la aplicación del juicio previsto en los artículos 53, 59 y 60 de la Constitución Nacional. En efecto, el propio texto constitucional excluye el indulto en caso de juicio político, tanto la destitución como su inhabilitación, en caso de que la hubiere.

En sentido contrario, Badeni (2005) ha señalado lo siguiente: "atendiendo al carácter jurisdiccional que le atribuimos a ese proceso público, entendemos que el indulto no es aplicable respecto de la remoción que disponga el Senado porque ella no reviste carácter penal. Pero sí se podría hacer efectivo respecto de la declaración de incapacidad que, como sanción accesoria, prevé el artículo 60" (pp. 46-47).

Por último, es pertinente especificar qué ocurre en la siguiente situación: si, como consecuencia de las investigaciones en la sede legislativa, se tramita un proceso penal y se lo encuentra responsable, es necesario señalar que en dicho caso sí es posible indultar; pues no se está indultado o conmutando el hecho y la autoría de lo investigado y sancionado por el Congreso, sino que se hace luego que se transitó un proceso penal en donde la sentencia adquirió - como hemos dicho antes- autoridad de cosa juzgada, aun cuando las circunstancias fácticas hubieran surgido a instancias de aquélla investigación.

\section{V.4. Sentencia pasada en autoridad de cosa juzgada}

Este requisito resulta ser el más controvertido en la doctrina, así como también de la jurisprudencia de nuestro país. Existen, básicamente, dos posturas contrapuestas. La primera, abrazada por una parte minoritaria de la disciplina vernácula y por la Corte Suprema de Justicia — "Riveros" (Fallos: 313:1392) y "Aquino" (Fallos: 315:2421)—, entiende que la redacción dada a la competencia presidencial habilita a indultar o conmutar la pena, tanto a procesados como a condenados. Por el contrario, la mayoría de la doctrina considera que sólo es posible beneficiar a los condenados con sentencia firme.

\section{V.4.1. Indulto a condenados}

En nuestra opinión, el indulto presidencial sólo puede recaer sobre una sentencia pasada en autoridad de cosa juzgada. En otras palabras, para que se pueda dictar un indulto, debe existir una pena por la comisión de un delito y sobre ésta no cabe recurso alguno. Como consecuencia, el indulto sólo puede beneficiar a condenados, excluyendo la posibilidad de que éste alcance a procesados. Otro tanto ocurre con la conmutación de penas. 
Preliminarmente, diremos que la redacción dada por los constituyentes nacionales es distinta a la prevista en la Constitución de los Estados Unidos. Si bien se la tuvo en consideración, no siguió sus pasos. De allí que podamos afirmar que no es posible extrapolar la doctrina o jurisprudencia de ese país y aplicarla sin beneficio de inventario. Si lo hacemos, podemos caer en el error de extender la competencia a situaciones no previstas por nuestra constitución. En efecto, mientras que la constitución norteamericana prevé la facultad de indultar y amnistiar, la nuestra establece dos competencias distintas asignadas a dos órganos diferentes. Otro tanto, ocurre con el requisito en examen. Nuestra cláusula es una creación autóctona que tuvo en cuenta nuestros antecedentes patrios.

En apoyo a esta postura, debemos citar, una vez más, el artículo 109 de nuestra Constitución, que reza: "en ningún caso el presidente de la Nación puede ejercer funciones judiciales, arrogarse el conocimiento de causas pendientes o restablecer las fenecidas", impidiéndole así al Ejecutivo inmiscuirse en causas judiciales. Si el Poder Ejecutivo pudiese indultar a procesados, ello supondría una intervención indebida, conforme la división de los poderes efectuada por la Constitución Nacional y supondría la posibilidad, real y concreta, de que el presidente de la Nación pueda tomar una causa en curso, quitársela al Tribunal interviniente y concluir el proceso mediante un indulto. Desde nuestra perspectiva, una interpretación favorable no resulta coherente ni sistémica con el resto de la Constitución. No nos parece válido tomar una cláusula de manera aislada y generar interpretaciones que no resulten compatibles con el resto del texto de la Ley Fundamental.

La única manera en que ambas cláusulas —es decir, los artículos 109 y 99, inciso 5- pueden coexistir sin contradicción es, justamente, cuando la competencia para indultar encuentra como límite al artículo 109. Consecuentemente, el Poder Ejecutivo no puede indultar procesados porque es algo que está prohibido en el citado artículo - arrogarse el conocimiento de causas pendientes-, permitiendo su aplicación únicamente cuando el tribunal haya concluido su actuación y se hayan agotado las vías procesales (es decir, cuando se tenga una sentencia pasada en autoridad de cosa juzgada).

En este mismo orden de ideas, debemos mencionar también al artículo 29, que establece la prohibición de que el Congreso le otorgue al Poder Ejecutivo facultades extraordinarias o la suma del poder público. Es decir, esta disposición impide que el Poder Ejecutivo arrogue para sí las funciones legislativas, administrativas y judiciales. Estando la causa en trámite ante un tribunal, resulta imposible que se pueda avocar a ella; todo bajo sanción - como establece la cláusula-de declarar la nulidad insanable y de sujetar a los que formulen, consientan o firmen dicho accionar, a la responsabilidad y pena de los infames traidores a la patria. 
Además, indultar a un procesado implica un desborde de las competencias presidenciales pues, en la práctica, supone no sólo dictar una amnistía con el ropaje de indulto (prerrogativa del Poder Legislativo), sino también entrometerse en las funciones propias del Poder Judicial. Según el artículo 18, sólo los jueces naturales pueden dirimir las causas con fuerza de autoridad.

Al respecto, Carlos Creus (1996) sostiene con claridad meridiana lo siguiente:

(...) de las expresiones de las fórmulas constitucionales (artículo 99, inc. 5, Constitución Nacional) y legales (artículo 68, Código Penal) (...) surge que el indulto se limita a ser causa de extinción de la pena, que no lo es de la acción procesal penal y que, por consiguiente, es inaplicable cuando aún no media sentencia firme, es decir, cuando no existe pena. Sin embargo, una y otra vez han insistido los poderes ejecutivos en hacer uso de esa facultad cuando el procesado está en curso, proceder que ha llegado a ser convalidado por fallos de la Corte Suprema de Justicia (pp. 467-468).

En un interesante artículo, Jorge Frías Caballero (1992) analiza las implicancias de un indulto practicado antes del dictamen judicial:

Todo ciudadano sometido a un proceso criminal tiene el derecho inviolable de exigir (en el estado de derecho) que recaiga a su respecto una sentencia judicial que le condene o absuelve y ese derecho legítimo lo tiene, en grado de excelso y superlativo, la persona que se debe inocente y a quien se le deniega el derecho de discutir y probar su inocencia; cargando sobre sus espaldas, de por vida, el estigma de un delito que acaso no cometió, ya que el indulto no borra el delito y eterniza la sospecha (p. 39).

Por su parte, José Manuel Estrada (1902) observaba lo siguiente: "devolver al inocente la fama perdida, integrándolo en todos los derechos de que le ha despojado el error o la maldad de los hombres, es obra de reparación y no de perdón. Éste supone la culpa, y la palabra perdón sería el insulto más sangriento, aplicado a un inocente que no ha merecido la pena que se le infligió" (p. 313).

Asimismo, debemos agregar que la aplicación del indulto sobre un procesado contraría el principio de inocencia (artículo 18) y la inviolabilidad en juicio de la persona, pues el indulto implica un "gracia" o "perdón" por el delito cometido. Además, dicha aplicación puede frustrar la actuación del Ministerio Público Fiscal, hoy órgano constitucional, y de las propias víctimas - particulares damnificados-. 
Como más adelante veremos, el beneficiado debe - desde nuestro punto de vista- prestar consentimiento, ya que, si no lo hace, se lo priva de una sentencia, derecho que lo asiste constitucionalmente (artículos 18, 19 y 75, inciso 22).

Por último, entendemos que el indulto no es aplicable sobre los procesados, porque ello implicaría una cancelación de la criminalidad de una conducta, es decir, una amnistía, competencia exclusiva, excluyente e indelegable del Poder Legislativo.

En consecuencia, consideramos que indultar a procesados es inconstitucional pues la cláusula en análisis requiere que haya recaído una pena pasada en autoridad de cosa juzgada, por un delito sujeto a jurisdicción federal.

\section{V.5. Motivación}

Previamente al desarrollo de la motivación, debemos aclarar que, desde nuestra perspectiva, es necesario que tanto el indulto como la conmutación de penas estén debidamente motivados. Nos oponemos así a la idea de que éstos carecen de dicho extremo fundándolo en su discrecionalidad. Por el contrario, consideramos que dicha situación debe estar presente como condición para su válida emisión.

Sentado ello, discurrimos que la motivación comprende una exposición razonada del presidente, en la que da cuenta de los motivos que lo han llevado a dictar el acto, mencionando - a su vez- los antecedentes de hecho ponderados que justifican su decisión y la competencia otorgada por la Constitución (derecho aplicable). La motivación debe estar incluida en el texto del acto de indulto o conmutación, mediante una exposición escrita.

En otras palabras, este requisito, que consiste en la exteriorización de las razones que justifican y fundamentan la emisión del acto, trata tanto de las circunstancias de hecho y de derecho (es decir, la "causa" del indulto o conmutación) como del interés público que se persigue con la medida (finalidad).

\section{V.6. Publicidad}

Del sistema republicano (artículo 1, Constitución Nacional) deriva la obligatoriedad, no sólo de notificar al interesado y demás partes del proceso penal, sino de hacer pública la disposición presidencial del indulto o conmutación de penas (acto), para lograr el conocimiento de la ciudadanía. Como sabemos, ésta es posterior al dictado e imprescindible, es decir, no puede haber indulto o conmutación de penas sin que el acto fuera puesto en conocimiento de la población. 
En ese orden, corresponde afirmar que el dictado de este tipo de medidas excede el interés del beneficiado, es decir, existe un verdadero y real interés en que toda la comunidad conozca el acto y los motivos que llevaron a dictarlo. A su vez, la divulgación es un elemento imprescindible para que se pueda controlar la actividad presidencial. Enfatizamos, para que se escrute públicamente la decisión.

En consecuencia, todo indulto o conmutación de penas que no haya sido publicada, no debería surtir efectos. Insistimos, la naturaleza del instituto, la excepcionalidad de su aplicación y la importancia institucional que reviste -recordemos que se entromete el ejecutivo en un proceso clausurado-, nos inclina por esta postura. Todo indulto o conmutación, como gracia que son, deben ser publicadas previamente.

Por último, es necesario especificar dónde se debe efectuar la publicación. El acto debe ser publicado en la primera sección del Boletín Oficial, denominada "Legislación y avisos oficiales" (4), en el soporte que se utilice en ese momento. En la actualidad, conviven el formato papel y el digital. En poco tiempo, podemos pronosticar, el primero será remplazado por el segundo. Asimismo, es razonable, su publicación en diarios de gran tirada, tanto nacionales como locales.

Es destacar que, en pos de lograr la finalidad mencionada, actualmente, las redes sociales resultan ser un medio idóneo para lograr dicho cometido. Claro está, de modo complementario al oficial.

\section{V.7. Acciones, personas o delitos excluidos}

A continuación, abordaremos el siguiente interrogante: ¿todos los delitos son indultables?, ¿o sólo algunos pueden ser objeto de esta medida?

\section{V.7.1. Artículos 15, 22, 29, 36 y 119 de la Constitución Nacional}

En primer lugar, excluiremos de la posibilidad de dictar el acto constitucional a las acciones alcanzadas por los denominados delitos constitucionales previstos en los artículos 15, 22, 29, 36 y 119.

(4) Además, existen otras tres, a saber: "Sociedades" (2a sección), “Contrataciones" ( $3^{a}$ sección) y "Dominios de internet” (4 a sección). Ver https://www.boletinoficial.gob.ar/ 


\section{V.7.2. Funcionarios públicos}

Consideramos que no es posible que el presidente se indulte a sí mismo o a cualquiera de los funcionarios de alto rango. Así, el vicepresidente, jefe de Gabinete, ministros o secretarios de Estado no podrán ser alcanzados con una medida de ese tenor. (5) La moral pública y la ética impiden un obrar de ese tenor. De no obrarse de esa manera, un funcionario público podría cometer un delito, renunciar y, posteriormente, verse favorecido por una gracia del Poder Ejecutivo. Por las mismas razones, no podrían ser indultados por delitos cometidos en ejercicio de sus funciones, los legisladores nacionales (diputados o senadores), ni tampoco, los miembros de la Corte Suprema.

El ejercicio de la función pública requiere que la persona que cometa cualquier tipo de delito vinculado al ejercicio o en ocasión de sus funciones, responda por él.

Tampoco podrán ser indultados o conmutados, las personas cercanas a los funcionarios mencionados precedentemente. Así, esposo/a, conviviente, hermanos, ascendientes y descendientes, quedarían excluidos.

\section{V.7.3. Delitos que deben estar excluidos}

Desde nuestra perspectiva, estos delitos deben quedar excluidos atento su importancia y significación institucional o social. A saber: 1) Delitos constitucionales (artículos 15, 22, 29, 36 y 119 de la Constitución Nacional); 2) Crímenes de Lesa de Humanidad; 3) Homicidios simples y agravados (artículos 78 y 79 del Código Penal); 4) Delitos contra la integridad sexual (artículos 119, 120, 124, 125, 125 bis, 126, 127, 128, 129, 130, 131, 132 y 133 del Código Penal); 5) Delitos contra la libertad. Delitos contra la trata de personas (artículos 140 al 149 ter del Código Penal). Para prevenir, reprimir y sancionar la trata de personas, especialmente mujeres y niños de la ONU, el Protocolo - aprobado por ley No 25.632- define la trata de personas del siguiente modo:

(...) la captación, el transporte, el traslado, la acogida o la recepción de personas, recurriendo a la amenaza o al uso de la fuerza u otras formas de coacción, al rapto, al fraude, al engaño, al abuso de poder o de una situación de vulnerabilidad o a la concesión o recepción de pagos o beneficios para obtener el consentimiento de una persona que tenga autoridad sobre otra, con fines de explotación. Esa explotación incluirá, como mínimo, la explotación de la prostitución ajena u otras

(5) Incorporamos a los ministros y al jefe de Gabinete, pues en ellos reposan las principales tareas -artículo 99 (inciso 7), 100, 101, 102 y concordantes de la Constitución-. 
formas de explotación sexual, los trabajos o servicios forzados, la esclavitud o las prácticas análogas a la esclavitud, la servidumbre o la extracción de órganos (Protocolo para prevenir, reprimir y sancionar la trata de personas especialmente mujeres y niños, artículo 3, inciso a).

6) Delitos contra los poderes públicos y el orden constitucional (artículos 226 a 236 del Código Penal); 7) Delitos contra la Administración Pública (artículos 241 bis, 246, 247, 248, 248 bis, 250, 250 bis, 251, 252, 253, 253 bis, 253 ter, 256, 256 bis, 257, 258, 258 bis, 259, 259 bis, 260, 261, 262, 263, 264, 265, 266, 267, 268 (1), 268 (2) y 268 (3), 269, 270, 271 y 272 del Código Penal); 8) Delitos aduaneros (artículo 862, 863/867, 868/870, 871/873 y 874/875); 9) Delitos referidos al tráfico de estupefacientes (modificaciones practicadas al articulado del Código Penal por la Ley No 27.737); 10) Delitos de lavado de activos.

\section{V.8. Consentimiento del beneficiario}

En nuestra opinión, atento que el indulto presupone la responsabilidad penal de la persona y no su inocencia, consideramos que el beneficiario de la medida debe prestar su conformidad. No nos parece correcto que esta medida se imponga a la persona sin que medie su consentimiento, atento a las consecuencias que, en materia penal, tiene su dictado.

Como hemos visto, nuestra Corte siguió, en este punto, lo establecido por la doctrina norteamericana y, consecuentemente, sostuvo que no se trata de un acto contractual, rechazando de este modo la posibilidad de que el beneficiario se oponga a la medida. A modo de ejemplo, podemos acercar el fallo "Daleo" (Fallos: 316:507) que, en uno de sus considerandos, explícitamente sostiene: "No cabe otorgar al indultado la facultad de negarse a aceptar la decisión presidencial". En la misma causa, en el voto de Boggiano, rezan las siguientes consideraciones:

Descartada la posible colisión del indulto a procesados con garantías constitucionales, no se advierte cuál podría ser la razón para sujetar esa medida a la renuncia del beneficiario o al dictado de una eventual sentencia condenatoria. (...) Los motivos que determinan el ejercicio de la atribución de indultar por parte del presidente de la Nación, exceden siempre el mero interés particular del indultado y atañen al interés general, lo que determina la imposibilidad de concebir este instituto como sujeto a aceptación y, menos aún, a acondicionamientos por parte del beneficiario (considerando noveno).

En apoyo a nuestra postura, diremos que toda persona tiene derecho a un proceso justo y a que una sentencia fundada resuelva la cuestión. Por lo que, si un procesado es beneficiado con un indulto o conmutación de penas, éste puede 
requerir un pronunciamiento expreso del poder judicial respecto a su responsabilidad penal o no. Creemos que, en este punto, los artículos 18, 33 y 75 (inciso 22) de la Constitución Nacional garantizan un acceso irrestricto de las personas a la justicia. Es decir, el imputado tiene todo el derecho de poder solicitar una sentencia judicial para que se respete, de este modo, el principio de inocencia que recae sobre él.

En este mismo orden de ideas, la persona beneficiaria podría esgrimir sus derechos a título de su honor y buen nombre, como también hacer referencia expresa a que, obrar en sentido contrario, vulneraría los principios de igualdad ante la ley y de legalidad.

Por último, discurrimos que no se puede obligar a quien no quiere ser beneficiado. Sería el caso de aquel que, teniendo sentencia pasada en autoridad de cosa juzgada, decide no aceptar el indulto. Múltiples razones podrían justificar tal determinación y creemos que, bajo ninguna situación o frase pomposa (por ejemplo, "fines de alta política"), puede justificarse su imposición.

\section{V.9. Participación de la víctima en el procedimiento}

A partir de lo especificado en el apartado anterior, surge la necesidad de hacer partícipes del procedimiento a la víctima o a sus familiares - en caso de impedimento o imposibilidad-y al Ministerio Público Fiscal.

La importancia de la participación de la víctima radica en que la misma está autorizada a manifestarse y expresar su parecer respecto de la medida que se pretende implementar. Obviar su participación - como se ha hecho hasta el presente- bajo el pretexto de ser una competencia discrecional del Poder Ejecutivo, implica desconocer los derechos que le asisten a las víctimas.

En relación con lo observado, se promueve que la víctima y el Ministerio Público Fiscal puedan manifestarse previamente, de modo tal que el presidente pueda contar también con ese tipo de información, de cara a la decisión. Se trata, como en el caso del informe previo, de enriquecer el procedimiento y robustecer la decisión. Cabe aclarar que dichas manifestaciones no obligan al presidente en un sentido u otro, pero sí es conveniente que el Ejecutivo las considere y se pronuncie sobre ellas.

Por último, podemos agregar que la participación de la víctima es susceptible de adoptar la forma que la misma considere más conveniente (presentación por escrito o audiencia, por ejemplo). En relación con el Ministerio Público, consideramos que su actuación se rige por sus propias normas (ley No 27.148 y modificaciones). 
ANÁLISIS CONSTITUCIONAL DEL INDULTO Y LA CONMUTACIÓN DE PENAS. ¿QUÉ REQUISITOS SE DEBEN CUMPLIR PARA SU LEGÍTIMA EMISIÓN? - ESTEBAN FEDERICO TAGLIANETTI (PP. 195-224)

\section{V.10. Audiencia Pública}

Actualmente, nuestra Constitución no prevé la participación de los ciudadanos en la toma de decisión. En este sentido, creemos que es necesario complementar la cláusula constitucional con una norma que así la contemple.

En efecto, seguir interpretando la norma como una "potestad discrecional" del Poder Ejecutivo - tal como, hasta el momento, se viene procediendo-, es continuar con una prédica monárquica, impropia del Estado de Derecho. Cabe recordar que, justamente, la existencia de un "Estado de Derecho" se da gracias a que la Ley, como construcción impersonal y en favor del bien común, alcanza también a los gobernantes. En otras palabras, se debe desterrar cualquier tipo de atribución de competencia que descanse en la idea de la "mera voluntad" del funcionario. Sumado a ello, como anverso de la misma moneda, debemos indicar que las personas que se encuentran bajo su jurisdicción quedan sujetas a un poder discrecional, carente de razón, que las coloca en una posición de pasividad y desigualdad impropia. Esto también es una manera de proceder menoscabando la dignidad de las personas.

Teniendo en consideración lo señalado, creemos que es pertinente establecer, de manera previa al dictado del acto constitucional, un espacio o ámbito de discusión, donde el Poder Ejecutivo se vea obligado a informar a la ciudadanía respecto de su voluntad de indultar o conmutar penas a un detenido, comunicando - al mismo tiempo- las razones que justifican su dictado y promoviendo la participación de la ciudadanía, mediante audiencias públicas que garanticen la pluralidad de voces. De esta manera, la decisión se vería robustecida.

Entendemos por "Audiencia Pública" el procedimiento público de participación, en el que se otorga al pueblo la garantía de informarse acabadamente (el órgano encargado debe poner a disposición del público, y de manera anticipada, información veraz, accesible y suficiente), se le permite realizar consultas -las cuales deberán ser respondidas en tiempo y forma- y, también, manifestar su opinión a favor o en contra, pudiendo expresarse en forma oral, informal y dentro de un plazo razonable, previamente estipulado. Estas audiencias deberán ser efectuadas en forma previa al dictado de una decisión que puede afectar sus derechos (en este caso, antes del dictado del acto constitucional de indulto o conmutación de penas).

Este procedimiento especial, como señalamos, es una instancia de participación en el iter de la toma de decisión, por medio del cual la autoridad responsable habilita un ámbito institucional de discusión para que todo ciudadano que lo desee, exprese sus opiniones y brinde sus fundamentos. 
Consideramos que las audiencias públicas permiten democratizar al poder y someterlo a examen. La participación ciudadana en el ejercicio del poder reconoce bases constitucionales y supranacionales. Por otra parte, observamos que, a partir de los avances en las TIC (tecnologías de la información y la comunicación), los ciudadanos pueden participar en audiencias en forma no presencial, mediante el empleo de tecnologías que permiten ver, escuchar e interactuar en tiempo real. Esto favorece decididamente la participación ciudadana, fomenta el escrutinio público y da mayor volumen a la discusión.

La finalidad de la existencia de audiencias públicas previas(6) es la misma que la del informe previo y la participación de la víctima y del Ministerio Público, es decir, dotar de mayor información al presidente, pero, además, la audiencia es un medio eficaz para que la sociedad tome conocimiento de manera previa a que el Poder Ejecutivo indulte o conmute. Es decir, publicita el futuro acto y le da visibilidad.

Este procedimiento especial permitirá la participación de organizaciones no gubernamentales, universidades, profesionales, organismos de derechos humanos e, incluso, si así lo desean el propio (futuro) beneficiario; así se robustece la decisión.

De lo dicho y actuado en la audiencia pública, se tendrá que confeccionar un informe que deberá ser anexado a las actuaciones. Por último, vale recordar que dicho informe no es vinculante para el presidente, pero deberá ponderarlo y manifestarse al respecto en el acto.

\section{Propuesta}

A partir de lo dicho, y a fin de condensar las ideas expuestas, consideramos que resulta pertinente llevar adelante una propuesta que tenga por objeto superar los problemas que hemos observado en la aplicación de las figuras. La misma consiste en que se dicte una norma que reglamente dicha competencia, ya que la práctica demuestra que la jurisprudencia de la Corte Suprema - como hemos visto- ha dado diversas respuestas a los mismos interrogantes. El dictado de una normativa de estas características permitiría unificar los criterios y, en consecuencia, lograr una aplicación homogénea de la prerrogativa presidencial.

Dicha regla deberá contemplar la participación de la víctima y de la ciudadanía en el proceso de toma de decisión, la delimitación de los delitos alcanzados

(6) Las audiencias públicas deben ser previas al acto, pues, en caso contrario, su cometido se ve desnaturalizado. 
(de manera taxativa, evitando cláusulas abiertas), los requisitos y la forma en que deben cumplirse los impedimentos y demás cuestiones referidas a la publicidad y difusión.

Asimismo, a fin de que los interesados se encuentren en un pie de igualdad, corresponde regular el procedimiento que debe llevarse a cabo para la correcta adopción de la medida.

\section{VI.1. Propuesta: Reglamentación del Indulto y la Conmutación de penas}

La norma deberá prever en su articulado los siguientes puntos:

1) Objeto: El Decreto tiene por objeto regular la concesión del indulto y la conmutación de las penas en los supuestos y con los alcances previstos en el artículo 99, inciso 5, de la Constitución Nacional y en esta norma.

2) Toda persona que se encuentre condenada podrá solicitar al presidente de la República que le otorgue el indulto o conmutación de la pena, siempre que cumpla con los requisitos establecidos en este Decreto.

3) De los que pueden ser indultados o conmutadas sus penas: 1) Personas alcanzadas: Los condenados por sentencia firme podrán, por sí o por terceros legitimados, presentar la solicitud de indulto o conmutación de la pena impuesta; 2) Delitos permitidos: aquellos que se consideren menores, tomando en cuenta la pena prevista por su comisión. Una fórmula abierta permitirá, adecuar la norma a los cambios que ocurran en la sociedad, pero actuando en conjunto con el listado de excluidos.

Por último, diremos que, más allá del proceso establecido para el dictado de decretos de este tenor en la Constitución, comprendemos que, en este caso, como otros tantos (7), resulta necesaria la participación pública en su debate. Es que la decisión respecto de los delitos no alcanzados por el indulto, debería ser fruto no sólo de la labor del Poder Ejecutivo sino también de todos los involucrados -incluidas, obviamente, las instituciones intermedias, ONG (organización no gubernamental), entre otras-. Eso le dará un mayor volumen de discusión y reflexión. Insistimos, a mayor información, menor probabilidad de error y mayor legitimación en la decisión tomada.

(7) El principio sería, en nuestro parecer, que las normas de alcance general emanadas del Poder Ejecutivo deberían prever la convocatoria a los grupos o personas afectadas para que puedan expresar su parecer de manera previa al dictado del decreto. 
4) Legitimados para solicitar el indulto: el penado, sus parientes o cualquiera otra persona en su nombre pueden solicitar el indulto sin necesidad de poder escrito que acredite su representación.

5) Clase y efectos del indulto: 1) El indulto será total; 2) El indulto de la pena principal llevará consigo las accesorias que en ésta hubiesen impuesto; 3) La concesión del indulto es, por su naturaleza, irrevocable con arreglo a las cláusulas con que hubiere sido otorgado; 4) El indulto no extingue la responsabilidad civil respecto de la víctima en proceso iniciado o concluido; 5) La solicitud o propuesta de indulto no suspenderá el cumplimiento de la sentencia ejecutoria; 6) El indulto o conmutación de pena no se extenderá a las costas procesales; 7) Los condenados por delitos cuya pena ha sido indultada o conmutada, se computan a los efectos de la reincidencia; 8) Un delito indultado puede ser tomado como una agravante al momento de sancionar un delito posterior por parte del Poder Judicial; 9) Autoridad de Aplicación: Ministerio de Justicia y Derechos Humanos.

6) Procedimiento:

6.1. La solicitud se presenta por el legitimado ante la Autoridad de Aplicación (Ministerio de Justicia).

6.2. El área técnica encargada deberá analizar si la solicitud reúne los requisitos para su tratamiento.

6.3. Requisitos: 1) Informe del Tribunal que dictó la sentencia en el cual se deberá consignar: nombre y apellido, edad, DNI, estado civil, antecedentes penales, número causa y órganos judiciales que hayan intervenido, sentencia condenatoria pasada en autoridad de cosa juzgada, forma en que se cometió el delito, las circunstancias agravantes o atenuantes tomadas en consideración, se informará si estuvo en prisión preventiva o no - en caso afirmativo, el auto que así lo dispuso-, si hay o no víctima u ofendido por el delito cometido, opinión respecto de la pertinencia de conceder el indulto, informe sobre la conducta del condenado en el establecimiento carcelario - de corresponder-, y cualquier otro dato que resulte conducente para la mejor ponderación de los hechos; 2) Informes médico, psicológico y psiquiátrico de la persona a indultar; 3) Para el caso que la solicitud no fuere solicitada por el condenado, éste deberá prestar su consentimiento de manera expresa; 4) Opinión de la víctima u ofendido si la hubiere. Ésta podrá ser hecha en forma verbal - en cuyo caso, se deberá redactar un acta a tal efectoo escrita a elección de la persona, ante la Autoridad de Aplicación. Obviamente, la participación de la víctima queda sujeta a su voluntad. No podrá, bajo ninguna circunstancia, constreñírsela a tal fin; 5) Audiencia Pública convocada por la Autoridad de Aplicación, a fin de garantizar una etapa de participación ciudadana en el proceso de toma de decisión; 6) Informe circunstanciado de los órganos 
dependientes de la Autoridad de Aplicación; 7) Dictamen de la Autoridad de Aplicación con la opinión positiva o negativa a la solicitud presentada; 8) El Presidente, de considerarlo pertinente, dictará el acto constitucional otorgando el indulto; 9) En el dictado del indulto se deberá consignar: lugar y fecha en que fue suscripto, nombre y apellido del beneficiario, DNI, clase y fecha a partir de la cual entra en vigencia la medida adoptada. Asimismo, instruirá a las áreas del servicio penitenciario y al juez a cargo de la ejecución penal, a fin de instrumentar la medida; 10) El Poder Ejecutivo deberá publicar los indultos en: Boletín Oficial y Página web oficial de la Autoridad de Aplicación, y diarios de mayor tirada. Además, deberá comunicárselo al órgano penal interviniente y al Poder Legislativo de la Nación. Se debería evaluar la posibilidad, como se dijo, la inclusión de las redes sociales; 11) El órgano encargado de la tramitación debería ser el Ministerio de Justicia y Derechos Humanos (Conforme el artículo 22, referido a las competencias del Ministerio referenciado, en su función 14 el texto reza: "Entender en los casos de indulto y conmutación de penas". Ley de Ministerio No 22.520 y modificaciones -la última por Decreto de Necesidad y Urgencia No 13/15-).

Por último, entendemos que la norma debe ser un decreto autónomo en los términos del artículo 99, inciso 1, de la Constitución Nacional, atento que estamos frente a una competencia exclusiva, privativa y excluyente del Poder Ejecutivo. Se tratará en definitiva de una autorregulación(8).

\section{Conclusiones}

La teoría de la división de los poderes es una doctrina que fue desarrollándose a lo largo del tiempo hasta su actual configuración. A su vez, cada país la adaptó según su idiosincrasia, conflictos, historia y realidad social, económica y jurídica.

Así, partiendo de dicha teoría, podemos afirmar la existencia de: 1) una distinción de las funciones jurídicas del Estado; 2) órganos separados (presidente, Congreso bicameral - diputados y senadores-, Corte Suprema de Justicia y tribunales inferiores) y 3) funciones determinadas para cada uno de los órganos mencionados.

A su vez, ha sido complementada por dos técnicas o teorías, a saber: 1) frenos y contrapesos - armas y escudos para los órganos, a fin de evitar los desbordes-, y

(8) Es más, atento la relevancia institucional de la temática y la -indudable- modificación de los criterios jurisprudenciales, consideramos que sería pertinente, en forma complementaria a la participación de la ciudadana, que el proyecto sea sometido al diálogo y discusión con los Poderes Judicial y Legislativo, con el objeto de robustecerlo. 
2) funciones compartidas - excluyendo la posibilidad de que actúen como compartimentos estancos-.

Mediante el otorgamiento del indulto y otras competencias, la Constitución de Estados Unidos previó que el Poder Ejecutivo pueda controlar y tener influenciar sobre el Poder Judicial, como un mecanismo para lograr el equilibrio entre los distintos poderes.

Siguiendo estos pasos, pero con otra redacción y alcance, nuestra Constitución también le atribuyó al presidente la competencia de indultar o conmutar penas impuestas por los jueces federales, previo informe del tribunal interviniente.

El indulto y la conmutación de penas quedan limitadas, a su vez, a las causas penales, quedando afuera, lógicamente, las civiles, contenciosas administrativas, laborales, agrarias, etc.

Esta competencia es exclusiva y excluyente del Poder Ejecutivo. El presidente se encuentra limitado por los requisitos expresos e implícitos de la Constitución, cuya violación acarrea la inconstitucionalidad del acto.

La competencia asignada debe interpretarse a luz de los principios y reglas establecidos por la Constitución. En especial, en lo que respecta al instituto examinado, por lo dispuesto en los artículos 109 (donde se prohíbe el ejercicio de la función judicial por parte del presidente o sus órganos dependientes), 29 (referido a la imposibilidad de que se le atribuya facultades extraordinarias o la suma del poder a persona alguna) y 23 (en cuanto la norma, aun en estado de sitio, prohíbe expresamente la posibilidad de que el presidente de aplicar penas) del texto fundamental.

El indulto o la conmutación de penas pueden solamente recaer sobre delitos de la jurisdicción federal. Es decir, las Provincias pueden regular este instituto en sus Constituciones, pero no tienen competencia para amnistiar, conforme la distribución de competencias hecha por la norma federal.

El indulto o conmutación es personal, no puede ser general, pues, en tal caso, se estaría violando el artículo 75 , inciso 20, que le atribuye la facultad de amnistiar al Poder Legislativo federal.

El indulto sólo puede alcanzar a condenados, excluyéndose la posibilidad de hacerlo a procesados. Previo a la toma de decisión por parte del presidente, consideramos que la decisión debe ser precedida de la participación de la víctima en el procedimiento y de una audiencia pública previa. Estas actuaciones le dan más volumen a la decisión y, atento la información que se generará, limitan el margen de error y obligan a una adecuada y suficiente motivación. 
Consideramos que el indulto solo puede aplicarse a delitos menores.

Por último, debemos enfatizar que el Derecho Internacional impide aplicar los institutos del indulto y la conmutación de penas (y, podríamos agregar, los de prescripción y amnistía), frente a casos de graves violaciones a los derechos humanos, pues han reputado este accionar como productor de impunidad(9). Así, tratándose de delitos de lesa humanidad, la CSJN individualiza tres obligaciones específicas: a) la obligación de "perseguir", b) la obligación de "investigar", y c) la obligación de "sancionar adecuadamente" a los responsables de tales delitos. Dichas obligaciones influirán directamente en la resolución judicial de los casos en los que se cuestione la constitucionalidad de indultos concedidos.

\section{Bibliografía}

Badeni, G. (2005). Indulto y conmutación de penas. Suplemento Especial La Ley $70^{\circ}$ Aniversario.

Bidart Campos, G. J. (1990). El indulto a procesados. El Derecho Jurisprudencia General, Universidad Católica Argentina, No 1990 (p. 135).

Bidart Campos, G. J. (1993). Tratado Elemental de Derecho Constitucional Argentino, T. II. Buenos Aires: Ediar.

Bidart Campos, G. J. (1997). Manual de la Constitución Reformada, T. III. Buenos Aires: Ediar.

Bielsa, R. A. (1959). Derecho Constitucional. Buenos Aires: Depalma.

Creus, C. (1996). Derecho Penal. Parte general. Buenos Aires: Astrea.

Ekmekdjian, M. Á. (2016). Tratado de Derecho Constitucional, T. V. Buenos Aires: Abeledo Perrot.

Estrada, J. M. (1927). Curso de derecho constitucional, T. III. Buenos Aires: Editorial Científica y Literaria Argentina.

Ferreira, M. (2007). Crímenes de lesa humanidad: Fundamentos y ámbitos de validez. En A. A. Gordillo; A. Loianno; G. Flax, Derechos Humanos (pp. 1-37). Buenos Aires: FDA.

(9) Ver: “Trabajadores Cesados del Congreso (Aguado Alfaro y otros) vs. Perú", del 30 de noviembre de 2007, entre otros. 
Frías Caballero, J. (1992). Indulto a procesados. Revista Jurídica Argentina La Ley, № 1992 C.

González Calderón, J. A. (1923). Derecho Constitucional Argentino: historia teoría y jurisprudencia de la constitución. T. III. Buenos Aires: Lajouane, SRL Editores.

González, J. V. (1951). Manual de la Constitución Argentina (1853-1860). 24 ed. Buenos Aires: Estrada.

Lazzarini, J. L. (1989). Indulto presidencial durante el proceso. Revista Jurídica La Ley, No 1989 D (pp. 1116-1122).

Marienhoff, M. S. (2011). Tratado de Derecho Administrativo. T. II. Buenos Aires: Abeledo Perrot.

Quiroga Lavié, H. (1993). Derecho Constitucional. Buenos Aires: Depalma.

Ravignani, E. (1937). Asambleas Constituyentes Argentinas: seguidas de los textos constitucionales, legislativos y pactos interprovinciales que organizaron políticamente la Nación; fuentes seleccionadas, coordinadas y anotadas en cumplimiento de la ley 11.857. T. IV (1827-1862). Buenos Aires: Universidad de Buenos Aires, Facultad de Filosofía y Letras, Instituto de Investigaciones Históricas.

Romero, C. E. (1976). Derecho Constitucional. Realidad política y ordenamiento jurídico. T. II. Buenos Aires: Zavalía.

Sagüés, N. (2017). Derecho Constitucional. T. II. Buenos Aires: Astrea.

Sánchez Viamonte, C. (1959). Manual de Derecho Constitucional. Buenos Aires: Kapelusz.

Soler, S. (1973). Derecho penal argentino. T. II. Buenos Aires: Tea.

Taglianetti, E. F. (2018). El indulto y la conmutación de penas en la Constitución Nacional. Análisis constitucional, jurisprudencial y doctrinario (Trabajo Final Integrador para acceder al título de especialista en Derecho Constitucional). Facultad de Ciencias Jurídicas y Sociales, Universidad Nacional de La Plata.

Zaffaroni, E.; Alagia, A. y Slokar, A. (2005). Manual de Derecho Penal: Parte General. Buenos Aires: Ediar.

\section{Legislación}

Constitución Nacional argentina. Artículos 1, 5, 14, 15, 18, 22, 23, 29, 33, 36, 75 (inc. 12, 20, 22), 99 (inc. 1, 5, 7), 100, 101, 102, 109, 119, 121, 123, 126. 
Código Penal argentino. Artículos 68, 78, 79, 119, 120, 124, 125, 125 bis, 126 a 133, 140 al 149 ter, 226 a 236, 241 bis, 246, 247, 248, 248 bis, 250, 250 bis, 251, 252, 253, 253 bis, 253 ter, 256, 256 bis, 257, 258, 258 bis, 259, 259 bis, 260, 261, 262, 263, 264, 265, 266, 267, 268 (1), 268 (2), 268 (3), 269, 270, 271 у 272.

Código Aduanero argentino. Artículos 862, 863/867, 868/870, 871/873 y 874/875.

Constitución de Estados Unidos. Artículo 2 (secc. 1, cl. 1).

Decreto del Poder ejecutivo Nacional No 13/15. Recuperado de http://servicios.infoleg.gob.ar/infolegInternet/anexos/255000-259999/256606/norma.htm [Fecha de consulta: 07/11/17].

Decretos 1002/89; 1003/89; 1004/89. Boletín Oficial de la República Argentina, Buenos Aires, 10/10/1989.

Decreto 2741/90. Boletín Oficial de la República Argentina, Buenos Aires, 03/01/1991.

Ley No 27.148. Boletín Oficial de la República Argentina, Buenos Aires, $18 / 06 / 2015$.

Ley No 27.372. Boletín Oficial de la República Argentina, Buenos Aires, $13 / 07 / 2017$.

Reglamento de la Corte Interamericana de Derechos Humanos.

\section{Jurisprudencia}

\section{Corte Suprema de Justicia de la Nación Argentina}

Fallos: 6:227, "Luengo".

Fallos: 136:244, "Ibáñez".

Fallos: 313:421, "Soto".

Fallos: 313:1392, "Riveros".

Fallos: 315:2421, "Aquino".

Fallos: 316:507, "Daleo".

Fallos 327:3312, "Arancibia Clavel". 
Fallos 328:2056, “Simón”.

Fallos 326:2805, "Videla"

Fallos: 330:3248, "Mazzeo".

Fallos: 333:1657, "Videla".

\section{Jurisprudencia Internacional}

“United Sates c/ Klein”, 13 Wall, 128. 147.

Fallo “Garland”, 2- Ex parte Garland, 4 Wallace, 333 (1867).

Corte I.D.H. (2007). “Caso Trabajadores Cesados del Congreso (Aguado Alfaro y otros) vs. Perú".

Corte I.D.H (2000). “Caso Bámaca Velásquez vs. Guatemala”.

Fecha de recepción: 28-03-2019 Fecha de aceptación: 12-09-2019 